\title{
Energy consumption and intensity of toll highway transport in Spain
}

\author{
P.J. Pérez-Martínez ${ }^{\mathrm{a}, *}$, R.M. Miranda ${ }^{\mathrm{b}}$ \\ ${ }^{a}$ Universidad Politécnica de Madrid, ETSIM-Grupo en Economía Sostenible del Medio Natural, C/Ramiro de Maeztu s/n, 28040 Madrid, Spain \\ ${ }^{\mathrm{b}}$ Universidad de São Paulo, Escuela de Artes, Ciencias y Humanidades, Av. Arlindo Béttio, 1000 Ermelino Matarazzo, CEP 03828-000 São Paulo, Brazil
}

Keywords:

Energy efficiency

Highway sections

Spanish tolled highways

Traffic conditions

\begin{abstract}
A B S T R A C T
We estimate the energy consumption of toll highway transport on a number of Spanish roads. Regression parameters are balanced according to coefficients from an empirical analysis based on survey data by vehicle type. The mean energy consumption and subsequent $\mathrm{CO}_{2}$ emissions on the toll highway sections are estimated as $1895 \mathrm{MJ} / \mathrm{h} / \mathrm{lane}-\mathrm{km}$ and $0.15 \mathrm{tCO}_{2}$ eq./h/lane- $\mathrm{km}$, values that increase to 2644 and 0.22 when energy and carbon emissions of transport infrastructure are considered based on the life cycle energy consumption for toll highway construction and use. If the energy intensity of infrastructure construction is allocated to the users according to traffic, it is much higher for motorcycles than for cars, and is significantly lower for articulated trucks than for vans.
\end{abstract}

\section{Introduction}

Energy savings through reduction of road transport demand on highways has traditionally focused on external cost amelioration related mostly to $\mathrm{CO}_{2}$ and pollutant emissions; decreasing the energy intensity (EI) has generally been less explored. However, the importance of $E I$ is currently increasing, and there are some studies focused on the monitoring of energy and environmental transport impacts per service unit offered. These studies are based on the development of transport sustainability, life cycle analysis ( $L C A)$ and intensity indicators. For instance, the material input per service unit (MIP) measures the potential for reducing energy and environmental impacts of transport per unit of product or service offered, thus serving as a transport intensity indicator.

Modal absolute energy consumption depends to a large extent on the amounts transported; be it passengers or tons. Activity data and energy consumption are used to analyze the intensity because it is determined by the energy required to move a vehicle and way its capacity is used. The energy required is determined by its fuel consumption, transport conditions, and vehicle characteristics. The use of its capacity depends upon occupancy and its load, its use, and the distribution of vehicles types in a fleet as a whole.

\section{Data and methodology}

Traffic on the $2928 \mathrm{~km}$ of Spain's high-capacity network toll highways in 2007 was 25,074 million vehicle-km, with an average daily flow (AADT) of 23,462. The Spanish Road Traffic Survey (SRTS) provides data on vehicle fleet distribution (MFO, 2009a): $76.2 \%$ of the traffic is cars, $12.8 \%$, trucks, $1.4 \%$ buses, $8.4 \%$ vans, and $1.2 \%$ motorcycles. The traffic data originates from permanent monitoring stations on sections of some Spanish toll highways and we focuses on toll roads because

\footnotetext{
* Corresponding author. Tel.: +34 913880721.

E-mail address: pj.perez@upm.es (P.J. Pérez-Martínez).
} 
Table 1

Traffic flow parameters for Spanish toll highways (2007). Source: Ministry of Public Works.

\begin{tabular}{|c|c|c|c|c|c|c|c|c|}
\hline Traffic parameter & Symbol & Mean & SD & Min & Max & Median & $\mathrm{CV}$ & Units \\
\hline Annual average daily traffic & AADT & 35,002 & 31,936 & 2,516 & 150,513 & 23,074 & 91 & veh/day \\
\hline Annual average hourly traffic per lane & AAHT & 560 & 402 & 46 & 1,816 & 454 & 72 & veh/h/lane \\
\hline Traffic density & $D$ & 5.76 & 5.81 & 0.41 & 49.7 & 4.08 & 101 & veh/km/lane \\
\hline Average travel speed & $v$ & 106.2 & 10.2 & 36.5 & 111.9 & 111.0 & 10 & $\mathrm{~km} / \mathrm{h}$ \\
\hline$\%$ AADT in the peak-hour & $k$ & 0.07 & 0.00 & 0.06 & 0.08 & 0.07 & 6 & $\%$ \\
\hline$\%$ Peak-hour traffic in the peak direction & $d$ & 0.56 & 0.04 & 0.51 & 0.67 & 0.55 & 8 & $\%$ \\
\hline Number of lanes per direction & $\eta$ & 2.3 & 0.5 & 2.0 & 4.0 & 2.0 & 21 & lanes \\
\hline Hourly volume gasoline cars & AAHT car $g$ & 119 & 91 & 11 & 419 & 89 & 77 & veh/h/lane \\
\hline Hourly volume diesel cars & AAHT car d & 287 & 220 & 26 & 1,015 & 215 & 77 & veh/h/lane \\
\hline Hourly volume vans & AAHT van & 57 & 47 & 3 & 235 & 45 & 82 & veh/h/lane \\
\hline Hourly volume motorcycles & AAHT motorcycle & 6 & 12 & 0 & 87 & 2 & 212 & veh/h/lane \\
\hline Hourly volume articulated heavy vehicles & AAHT art. truck & 54 & 40 & 1 & 160 & 48 & 74 & veh/h/lane \\
\hline Hourly volume rigid vehicles & AAHT rig. truck & 36 & 27 & 1 & 139 & 33 & 75 & veh/h/lane \\
\hline Hourly volume buses & AAHT bus & 2 & 2 & 0 & 9 & 1 & 81 & veh/h/lane \\
\hline Proportion of heavy duty traffic & $p$ & 14.3 & 8.2 & 1.5 & 43.0 & 14.0 & 57.1 & $\%$ \\
\hline
\end{tabular}

these are less used and thus offer a larger margin for improving their energy efficiency and it is easier to define suitable policies to reduce energy consumption and emissions. We consider the case of 202 sections in 2007, $1869 \mathrm{~km}$ in length, involving 19,837 million-vehicle-km and carrying 35,002 vehicles per day. Micro-level traffic parameters, such as AADT, percentage of HDVs (p-HDV), mean speed $(v)$ and annual average hourly traffic (AAHT) per lane are examined. The sections average 2.3 lanes in each direction with passenger cars dominating the traffic flow at 29,384 vehicles per day average over working days and weekends. HDVs account for about $14.3 \%$ of traffic, although significantly less on weekends. Table 1 contains details.

The method used to estimate the energy consumption and $\mathrm{CO}_{2}$ emissions from the highways is similar to that used by the Spanish Ministry of Environment (MMA, 2009) for the national emission inventory (NEI), and based on the EU Corinair report (EMEP/CORINAIR, 2009). Vehicle category and fuel consumption data for 2007 (MFO, 2009a) is used, combined with the permanent road freight sample survey (PRFSS), the road transport passenger survey (MFO, 2009b) and fuel-efficiency data from the Copert model (Ntziachristos and Samaras, 2000). The Corinair fuel consumption factors ( $f$ ), is adapted to Spanish traffic conditions on toll highways, driving standards and fuel characteristics to estimate energy consumption and $\mathrm{CO}_{2}$ emissions.

The energy consumption and $\mathrm{CO}_{2}$ emissions of a toll highway section $k$ are estimated using:

$$
\begin{aligned}
& E_{k}=\sum_{i} \sum_{j} f_{i, j} \cdot N C V_{j} \cdot A A H T_{i, j} \\
& C_{k, i}=E_{k, i, j} \cdot C E F_{j}
\end{aligned}
$$

where $E_{k}$ is the energy consumption of section $k$, expressed in mega-joules $\left(\mathrm{MJ}=10^{6} \mathrm{~J}\right)$ per hour and lane kilometre $(\mathrm{MJ} / \mathrm{h} /$ lane-km); $f_{i, j}$ is the fuel consumption factor of vehicle type $i$ using energy source $j$, in grams of oil equivalent per vehicle-kilometre (goe/vehicle-km); $N C V_{j}$ is the net calorific value of fuel $j$, in $\mathrm{MJ}$ per goe (MJ/goe); $A A H T_{i, j}$ is the traffic of vehicle type $i$ using energy source $j$, in vehicles per hour and per lane (vehicle/h/lane); $C_{k}$ are the $\mathrm{CO}_{2}$ emissions of section $k$, in tons of $\mathrm{CO}_{2}$ equivalent ( $\mathrm{tCO}_{2}$ eq.) per hour and lane kilometre $\left(\mathrm{tCO}_{2}\right.$ eq./h/lane-km), and $C E F_{j}$ is the carbon emission factor for fuel $j$, in tons of $\mathrm{CO}_{2}$ equivalent per tera-joule $\left(\mathrm{TJ}=10^{12} \mathrm{~J}, \mathrm{tCO}_{2}\right.$ eq./TJ). Fuel consumption available in grams of gasoline and diesel per hour lane-km (goe/h/lane-km), are converted into energy units (mega-joules, MJ) using the fuel's NCV. Analogously, $\mathrm{CO}_{2}$ emissions are estimated in tons of $\mathrm{CO}_{2}$ from energy consumption through the $C E F{ }^{1}$

Uncertainties in the estimation of energy consumption and $\mathrm{CO}_{2}$ emissions can be addressed by an appropriate allocation of activity and fuel data across types of road vehicles (Kühlwein and Friedrich, 2005). Therefore, appropriate country-specific Corinair fuel consumption factors must be used. Based on the distribution of the Spanish fleet (by vehicle type and age), technology of vehicles (EURO emission standards) and engine capacity, the mean consumption factors from the Copert model were weighted. These factors characterise the mean energy consumption of vehicles and are related to vehicle operation speed $(v)$. The weighting parameters used in the estimation of the consumption factors are summarised in Table 2 for all age groups and engine capacities (LDVs) and for all age groups, load capacities and load factors (HDVs).

Consumption factors depend on vehicle speed $(v)$; the slope coefficient, which measures the percentage effect of the slope of the highway section (s), and the roughness coefficient, which measures the effect of the international roughness index $(r)$ in $\mathrm{mm} / \mathrm{m}$. Fuel consumption increases as $s$ and $r$ increase. Park and Rakha (2006) looking at slope effects on the fuel consumption of Californian vans in a free flow scenario and at a constant speed of $64 \mathrm{~km} / \mathrm{h}$ found an increase in fuel consumption of $140 \%$ when the slope increased increases from $0 \%$ to $6 \%$ (from 68.1 to 163.5 goe $/ \mathrm{km}$ ). Boriboonsomsin and Barth (2009) found a similar relationship. At a constant speed of $96 \mathrm{~km} / \mathrm{h}$, an increase in section slope of $6 \%$ results in a $138.3 \%$

1 The NCV and CEF values used are from Schipper (2009): $0.036 \mathrm{MJ} /$ goe (gasoline), $0.039 \mathrm{MJ} /$ goe (diesel), $86 \mathrm{tCO} \mathrm{CO}_{2}$ eq./TJ (gasoline) and $81 \mathrm{tCO}{ }_{2}$ eq./TJ (diesel). 
Table 2

Summary table including weighting parameters used in fuel consumption factor estimation.

\begin{tabular}{|c|c|c|c|}
\hline Vehicle type & Technology (EURO) & Engine capacity (1), GVW (t) & Loading factor (no units) \\
\hline \multicolumn{4}{|l|}{$L D V s$} \\
\hline \multirow{3}{*}{ Gasoline cars } & After EURO I (66.0\%) & $<1.41(46.8 \%)$ & - \\
\hline & & $1.4-21(41.8 \%)$ & \\
\hline & & $>21(11.4 \%)$ & \\
\hline \multirow[t]{3}{*}{ Diesel cars } & EURO IV (31.8\%) & $<21(88.7 \%)$ & - \\
\hline & EURO III (32.3\%) & & \\
\hline & EURO II (26.2\%) & & \\
\hline Diesel vans & After EURO I (80.6\%) & - & - \\
\hline \multirow[t]{2}{*}{ Motorcycles } & Prev. EURO I (38.5\%) & $<0.251(<50 \%)$ & - \\
\hline & & Four times $(90.6 \%)$ & \\
\hline \multicolumn{4}{|l|}{ HDVs } \\
\hline \multirow[t]{3}{*}{ Articulated trucks } & After EURO II (62.7\%) & $<28 \mathrm{t}(56.9 \%)$ & Full load (38.5\%) \\
\hline & & $28-40 \mathrm{t}(31.8 \%)$ & Half load (38.5\%) \\
\hline & & $>40 \mathrm{t}(11.3 \%)$ & Empty (22.9\%) \\
\hline \multirow[t]{5}{*}{ Rigid trucks } & After EURO II (62.7\%) & $<12 \mathrm{t}(23.5 \%)$ & Full load (37.5\%) \\
\hline & & $28-40$ t $(28.8 \%)$ & Half load (37.5\%) \\
\hline & & $28-40 \mathrm{t}(25.2 \%)$ & Empty $(25.0 \%)$ \\
\hline & & $28-40$ t (19.0\%) & \\
\hline & & $>40 \mathrm{t}(3.5 \%)$ & \\
\hline \multirow[t]{3}{*}{ Buses } & After EURO II (59.4\%) & $<18 \mathrm{t}(56.9 \%)$ & Full load (34.5\%) \\
\hline & & $>18 \mathrm{t}(11.3 \%)$ & Half load (34.5\%) \\
\hline & & & Empty $(31.0 \%)$ \\
\hline
\end{tabular}

increase in gasoline car consumption from 42.1 to $100.4 \mathrm{goe} / \mathrm{km}$. The Copert model also measures the effect of slope on energy consumption by HDVs.

In terms of the influence of highway surface on energy consumption, Cenek (1994) finds that a decrease in $r$ from 5.7 to 2.7 results in a $4 \%$ reduction in fuel consumption by LDVs, while Burguess and Choi (2003) find a $10 \%$ potential improvement in $r$ and a subsequent 3\% reduction in fuel consumption by LDVs in the UK. Road pavement has only a minor effect because all highway sections have bituminous surfaces. Depending on speed, we assume that a $5 \%$ increase in the slope of the highway results in a $50-160 \%$ increase in consumption by LDVs and a $60-220 \%$ by HDVs. The effect of roughness of the pavement on consumption is much lower; a $5-15 \%$ increase for LDVs and a $6-20 \%$ for HDVs.

Calculation of the EI of Spanish toll highways during the exploitation phase is based on data on the construction of the transport infrastructures and data on the use of vehicles. The EI of toll highway transport section $k$, vehicle $i$ and fuel $j$, expressed in MJ per vehicle-km (MJ/vehicle-km), is estimated using:

$$
E I_{k, i, j}=\left[X_{k} \cdot\left(\frac{1}{A A D T_{k} \cdot p_{i, j} \cdot 365 \cdot c v_{k}}\right)+Y_{i, j}\left(\frac{1}{c v_{i, j}}\right)\right]
$$

where $X_{k}$ is the intensity of infrastructure $k(\mathrm{MJ} / \mathrm{km}), A A D T_{k}$ is the annual average daily traffic on toll highway section $k$ (vehicles/day), $p_{i, j}$ is the percentage of average daily traffic related to vehicle type $i$ using fuel technology $j, c v_{k}$ is the life cycle of infrastructure $k$ (30 years), $Y_{i, j}$ is the intensity of vehicle $i$ and fuel $j\left(\mathrm{MJ} /\right.$ vehicle) and $c v_{i, j}$ is the life cycle of vehicle $i$ using fuel $j$ $\left(270 \times 10^{3}\right.$ gasoline and diesel car kilometres, $400 \times 10^{3}$ diesel van kilometres and $1000 \times 10^{3}$ truck kilometres). The mean value of infrastructure intensity is assumed to be $28.1 \times 10^{6} \mathrm{MJ}$ per kilometre (González Díaz and García Navarro, 2009). The equation has two parts: the infrastructure's life cycle energy consumption divided by the traffic during the road's service life of 30 years and the vehicles' life cycle energy consumption divided by the number of kilometres driven. The second part relates to vehicle consumption factors ( $f_{i, j}$ in MJ per vehicle-km) where $Y$ is defined by multiplying $f_{i, j}, N C V_{j}$ and $c v_{i j}$, and relates to Eqs. (1) and (2). The parameter estimates are calculated for each section.

Dividing Eq. (3) by the number of passengers and freight tonnage transported, Eq. (4) gives MJ per passenger-km or ton-km (MJ/p-km, MJ/t-km):

$$
E I_{k, i, j}^{*}=\frac{E I_{k, i, j}}{f o_{i, j}}
$$

where $f_{i, j}$ is the occupancy rate or load factor of $i$ and $j$, assuming an average capacity utilisation for motorcycles, cars and buses of 1.2, 1.9 and 18 passengers. The average tonnages transported of vans, rigid trucks and articulated trucks are $0.5,4.5$ and 7.2 tons (MFO, 2009b).

Finally, the aggregate $E I$ of toll highway section $k$ is estimated in mega-joules per transport unit (tu) kilometre (MJ/tu-km, tu: passenger-km: ton-km) using:

$$
E I_{k}^{*}=\sum_{i} \sum_{j} p_{i, j} \cdot E I_{k, i, j}^{*}
$$




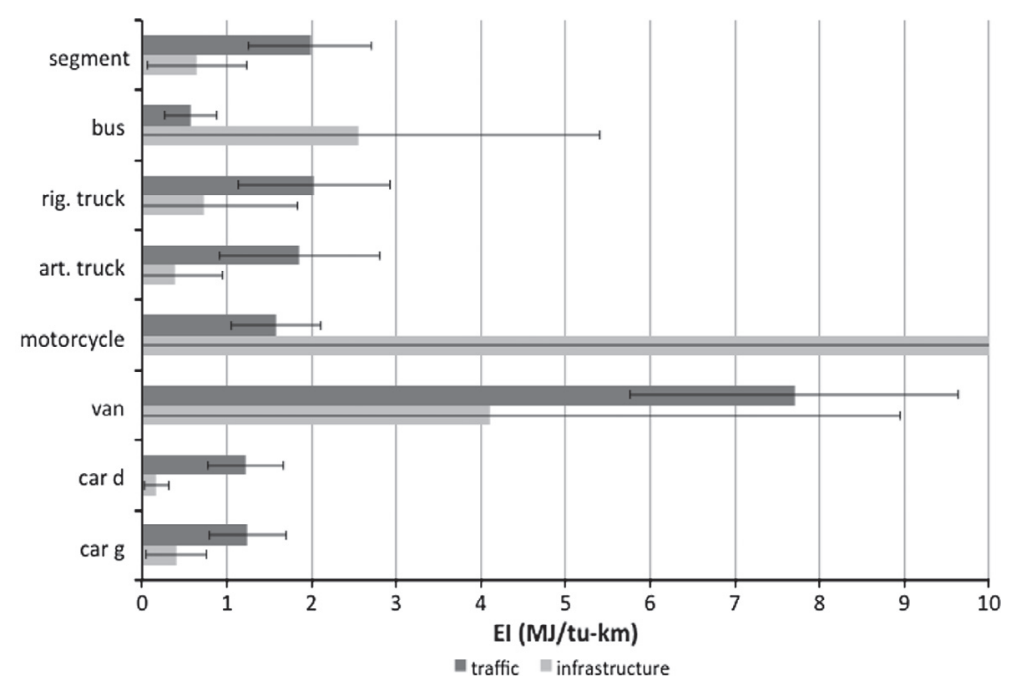

Fig. 1. El estimates, infrastructure and traffic, for passenger and freight transport vehicles with infrastructure allocated according to traffic. Note: Error bars represent $E I$ uncertainty expressed as standard deviation of section estimates; $E I$ (infrastructure) of van and motorcycle from 4.1 to $27.5 \mathrm{MJ}$ per transport unit kilometre.

where $p_{i, j}$ is the percentage of vehicle type $i$ using fuel $j$ when the infrastructure is allocated according to traffic volume by vehicle type (tu is 1 passenger-km and 1 ton-km).

\section{Results}

Estimates of mean energy consumption and $\mathrm{CO}_{2}$ emissions broken down by vehicle type are calculated using data from different sources. The mean energy consumption and subsequent $\mathrm{CO}_{2}$ emissions on the toll highway sections are estimated to be $1895( \pm 1215) \mathrm{MJ} / \mathrm{h} / \mathrm{lane}-\mathrm{km}$ and $0.15( \pm 0.10) \mathrm{tCO}_{2}$ eq./h/lane-km; the numbers in parentheses represent the uncertainties estimated by the standard deviation of the mean. These values increase to 2644 and 0.22 when energy and carbon emissions of the transport infrastructure are considered; about $28 \%$ of energy is attributed to infrastructure construction and maintenance. The mean energy consumption broken down by vehicles categories is $345 \mathrm{MJ} / \mathrm{h} / \mathrm{lane}-\mathrm{km}$ for gasoline cars, 672 for diesel cars, 292 for vans, 116 for motorcycles, 707 for articulated trucks, 387 for rigid trucks and 124 for buses. Freight vehicles, with an average of $1386 \mathrm{MJ} / \mathrm{h} / \mathrm{lane}-\mathrm{km}$, have the greatest energy consumption and $\mathrm{CO}_{2}$ emissions.

EI estimates by vehicle type are calculated using Eqs. (4) and (5) (Fig. 1) and broken down by traffic and transport infrastructure use. Large differences in average $E I$ in terms of mega-joules consumed per tu-km can be seen between vehicles. The calculations suggest Spain's tolled highway sections require $2.6 \mathrm{MJ} / \mathrm{tu}-\mathrm{km} ; 0.6$ infrastructure and 2.0 traffic use of energy, varying between 1.4 for diesel cars, and 29.1 for motorcycles. Similarly, in aggregate, gasoline car and diesel van transport requires between 1.6 and $11.8 \mathrm{MJ} / \mathrm{tu}-\mathrm{km}$; values are similar to those found in Saari et al. (2007) and Pérez-Martínez and Sorba (2010).

Considering traffic use, as expected, mass passenger modes consume less energy per transport unit than private transport, while for freight transport articulated trucks consume much less energy per tu-km than vans. But there are large variation in energy consumption per transport unit, depending on vehicle and fuel type; buses have EI values similar to those for trucks and gasoline cars have values of over $1.6 \mathrm{MJ} / \mathrm{tu}-\mathrm{km}$. Considering combined traffic and infrastructure use, the most inefficient modes using gasoline and diesel technologies are motorcycles and diesel vans, due to their low load factors. Considering only infrastructure use, motorcycles, vans and buses consume more energy per transport unit due to low AAHTs. Differences in EI between passenger and freight transport modes are similar for gasoline- and diesel-powered vehicles.

In terms of statistical significance, ANOVA test confirm significance of the mean EI and that the EI estimates for the twos slope differ and increase with slope. Similarly, the energy consumption estimates for the toll highway sections for the $10 \%$ and 30\% level of HDVs show an increasing and highly significant trend. Significant differences between vehicle types, section energy consumption, and $E I$ estimates are also observed. Sensitivity analysis of the input parameters defining energy consumption in Eq. (1) and EI in Eq. (3) show that increasing the input parameters by $20 \%$ results energy consumption increases significantly by $13.3 \%, 12.7 \%$ and $8.6 \%$, while increasing the input parameters by $20 \%, E I$ increases by $9.3 \%, 7.0 \%, 6.3 \%$ and $5.8 \%$.

\section{Conclusions}

The paper has examined the energy consumption and interurban toll highway transport in Spain. The energy intensities of the 202 sections studied carry 79.1\% of traffic on the country's toll highways but relatively little traffic compared with free 
highways; EI values for cars are many times lower than those for motorcycles. The energy intensity of buses is significantly higher than that of cars because of the greater infrastructure resources required. Equally, while the EI values for articulated trucks are significantly lower than those for rigid trucks, the values for vans are many times higher likely because of capacity variations across the vehicle types. Regarding the various road sections most of the differences found in $E I$ are due to the highways' slopes.

\section{References}

Boriboonsomsin, K., Barth, M., 2009. Impacts of road grade on fuel consumption and carbon dioxide emissions evidenced by use of advanced navigation systems. Transport. Res. Rec. 2139, 21-30.

Burguess, S.C., Choi, M.J., 2003. A parametric study of the energy demands of car transportation. Transport. Res. Part D 8, 21-36.

Cenek, P.D., 1994. Rolling Resistance Characteristics of New Zealand Roads. Transit New Zealand Research Report PR3-001, Wellington.

EMEP/CORINAIR, 2009. Emission Inventory Guidebook, third ed., September 2009 Update. Technical Report. European Environment Agency, EEA, Copenhagen.

González Díaz, M.J., García Navarro, J., 2009. Criteria and methodology for an indicator of energy applied to motorways. Presented at 2nd International Conference Ravage of the Planet 2009, Cape Town.

Kühlwein, J., Friedrich, R., 2005. Traffic measurements and high-performance modelling of motorway emission rates. Atmos. Environ. 39, $5722-5736$.

MFO, 2009a. Traffic Map, Transport and Postal Services 2008. Ministry of Development, Publications Centre, General Technical Secretariat, Madrid.

MFO, 2009b. Monitoring of Road Passenger Transport and Continuing Survey of Road Freight Transport 2008. Publications Centre, General Technical Secretariat, Ministry of Development, Madrid.

MMA, 2009. Inventory of Greenhouse Gases in Spain-Edit 2009, Summary of Results. General Environmental Quality Branch, Ministry of Environment, Madrid.

Ntziachristos, L., Samaras, Z., 2000. COPERT III Computer Programme to Calculate Emissions from Road Transport. European Environment Agency, Copenhagen.

Park, S., Rakha, H., 2006. Energy and environmental impacts of roadway grades. Transport. Res. Rec. 1987, 148-160.

Pérez-Martínez, P.J., Sorba, I., 2010. Energy consumption of passenger land transport modes. Energy Environ. 21, 577-600.

Saari, A., Lettenmeier, M., Pusenius, K., Hakkarainen, E., 2007. Influence of vehicle type and road category on natural resource consumption in road transport. Transport. Res. Part D 12, 23-32.

Schipper, L., 2009. Fuel economy, vehicle use and other factors affecting $\mathrm{CO}_{2}$ emissions from transport. Energy Policy 37, 3711-3713. 